\title{
1 Influence of the sunflower rhizosphere on the biodegradation of 2 PAHs in soil
}

$4 \quad{ }^{1}$ M.C. Tejeda-Agredano ${ }^{\mathrm{a}},{ }^{2} \mathrm{~S}$. Gallego,${ }^{\mathrm{b}} \mathrm{J}$. Vila, ${ }^{2}$ M. Grifoll, ${ }^{1} \mathrm{~J} . J$. Ortega-Calvo, ${ }^{1 *}$ M. Cantos

$5{ }^{1}$ Instituto de Recursos Naturales y Agrobiología, CSIC, Avda. Reina Mercedes, 10, 41012,

6 Sevilla, Spain

$7 \quad{ }^{2}$ Departament de Microbiologia, Universitat de Barcelona, Avda. Diagonal, 645, 08028,

8 Barcelona, Spain

10 Abstract

12 Reduced bioavailability to soil microorganisms is probably the most limiting factor in the 13 bioremediation of polycyclic aromatic hydrocarbons PAH-polluted soils. We used sunflowers 14 planted in pots containing soil to determine the influence of the rhizosphere on the ability of soil 15 microbiota to reduce PAH levels. The concentration of total PAHs decreased by $93 \%$ in 90 days 16 when the contaminated soil was cultivated with sunflowers, representing an improvement of $16 \%$ 17 compared to contaminated soil without plants. This greater extent of PAH degradation was 18 consistent with the positive effect of the rhizosphere in selectively stimulating the growth of 19 PAH-degrading populations. Molecular analysis revealed that the increase in the number of 20 degraders was accompanied by a dramatic shift in the structure of the bacterial soil community

21 favoring groups with a well-known PAH-degrading capacity, such as Sphingomonas ( $\alpha$ -

22 Proteobacteria), Commamonas and Oxalobacteria ( $\beta$-Proteobacteria), and Xhanthomonas ( $\gamma$ -

23 Proteobacteria). Other groups that were promoted for which degrading activity has not been

24 reported included Methylophyllus ( $\beta$-Proteobacteria) and the recently described phyla

25 Acidobacteria and Gemmatimonadetes. We also conducted mineralization experiments on 26 creosote-polluted soil in the presence and absence of sunflower root exudates to advance our 27 understanding of the ability of these exudates to serve as bio-stimulants in the degradation of 28 PAHs. By conducting greenhouse and mineralization experiments, we separated the chemical 29 impact of the root exudates from any root surface phenomena, as sorption of contaminants to the 30 roots, indicating that sunflower root exudates have the potential to increase the degradation of 31 xenobiotics due to its influence on the soil microorganisms, where sunflower root exudates act 
32 improving the availability of the contaminant to be degraded. We characterized the sunflower

33 exudates in vitro to determine the total organic carbon (TOC) and its chemical composition. Our

34 results indicate that the rhizosphere promotes the degradation of PAHs by increasing the

35 biodegradation of the pollutants and the number and diversity of PAH degraders. We propose that

36 the biostimulation exerted by the plants is based on the chemical composition of the exudates.

37

38 Keywords: rhizosphere, microbial community structure, bioremediation, PAHs, sunflower root

39 exudates, biodegradation

40

$41 \quad{ }^{*}$ Corresponding author tel: (+34) 5-4624711; fax: (+34) 5-4624002; e-mail: cantos@,irnase.csic.es

$42 \mathrm{a}, \mathrm{b}$ Both of these authors contributed equally to this work. 


\section{Introduction}

44 Bioremediation techniques are routinely applied to recover soils polluted by polycyclic aromatic hydrocarbons (PAHs). These techniques are based on the well-established capability of soil microorganisms to degrade PAHs through growth-linked or co-metabolic reactions (Kanaly and Harayama, 2010). However, a major limiting factor in the bioremediation of PAH-polluted soils is the reduced bioaccessibility that is often exhibited by these pollutants, which results in difficulty in predicting whether an acceptable end-point decontamination level can be achieved. Bioacessibility can be defined as the fraction of a pollutant that is potentially biodegradable over time in the absence of limitations to biodegradation other than restricted phase exchanges. Microorganisms can potentially overcome bioaccessibility restrictions through a variety of mechanisms, including biosurfactant production, attachment and chemotaxis (Tejeda-Agredano et al., 2011). Bioaccessibility can also be increased in the soil externally, for example, by adding surfactants (Bueno-Montes et al., 2011).

Rhizoremediation, i.e., the use of ecosystem services provided by the plant rhizosphere to decontaminate polluted soils, has recently gained attention in relation to organic pollutants, such as PAHs. Translocation of dissolved contaminants in the rhizosphere and the microbial utilization of root exudates as co-substrates in the biodegradation of PAHs have been proposed as mechanisms through which plants contribute to the elimination of PAHs (Newman and Reynolds,

61 2004). The sunflower (Helianthus annuus, L) has been used as a pilot system in phytoremediation assays for PAHs. The sunflower rhizosphere removes a greater quantity of

63 fluorene, anthracene and pyrene from contaminated soil than the rhizospheres of other plant species, such as wheat, oat and maize and exhibits a better response to seed germination and root elongation in the presence of these PAHs (Maliszewska-Kordybach and Smreczak, 2000). Olson et al. (2007) reported the sunflower as the best plant among 11 dicotyledonous species to use in assays of PAH bioavailability. Further advantages of focusing on the sunflower as a model plant for use in PAH rhizoremediation studies are related to the importance of this species as an edible oil producer. The ability to investigate the root exudation process and the role of the exudates under natural conditions has been hampered by a number of significant quantification problems,

71 due to interference by microbial metabolites and components of the soil (Grayston et al., 1996).

72 These problems can be overcome through the development of appropriate in vitro techniques to 73 obtain root exudates that allow analysis of the products secreted by the plant roots. 
The research approach applied in the present study was to generate soils polluted with aged PAHs at concentrations that would be realistic for polluted soils that had undergone extensive bioremediation, and we used these samples to test the hypothesis that the germination and development of sunflower plants would enhance the bioaccessibility and biodegradation of PAHs in the soil. We used both culture-dependent and culture-independent (i.e., based on DNA) techniques to determine the effects of planting on the dissipation of the chemicals from the soil under greenhouse conditions and on the structure of the soil microbial communities. We also developed a method to produce sunflower root exudates, which were chemically characterized and tested for possible effects on biodegradation by soil microorganisms through a dual radiorespirometry/residue analysis method that allowed precise estimation of compound biodegradation.

\section{Materials and methods}

\subsection{Soil}

Two soils were used in this study: a creosote-polluted clay soil and an agricultural soil. The polluted soil (Calcaric Fluvisol) constituted the source of aged contaminants as well as PAHdegrading microorganisms for our greenhouse and laboratory experiments. This soil was provided by EMGRISA (Madrid, Spain) from a wood-treating facility in southern Spain that had a record of creosote pollution exceeding 100 years. The agricultural, non-polluted soil was a loamy sand soil from Coria del Río, Seville, Spain (Typic Xerochrepts). A PAH-containing soil mixture was obtained from these soils in two steps. First, the agricultural soil was mixed (67:33 w/w) with washed sand (Aquarama), and subsequently autoclaved. Next, $6 \mathrm{Kg}$ of this mixture (referred to as uncontaminated soil) was homogenized with polluted soil $(1: 1 \mathrm{w} / \mathrm{w})$ in a cement mixer for seven days ( 9 hours per day), with regular changes in the direction of rotation. This homogenization period was necessary to allow reproducible results to be obtained. The mixture was then dried for 18 hours at $30^{\circ} \mathrm{C}$, ground and sieved ( $2 \mathrm{~mm}$ mesh). The resulting material was used in all experiments as a source of polluted soil with the following composition: $\mathrm{pH} 8.1$; $15.9 \% \mathrm{CaCO}_{3} ; 0.9 \%$ total organic carbon (TOC); $0.055 \%$ organic nitrogen (Kjeldahl); $7 \mathrm{mg} \mathrm{kg}^{-1}$ available phosphorus; $461 \mathrm{mg} \mathrm{kg}^{-1}$ potassium; particle size distribution $46.6 \%$ coarse-grained sand, $4.3 \%$ fine-grained sand, $15.8 \%$ silt, and $33.2 \%$ clay and $21.75 \mathrm{mgkg}^{-1}$ of total PAHs (as the 
sum of 6 PAHs: fluorene, phenanthrene, anthracene, fluoranthene, pyrene and chrysene; Table 1).

106 The resulting profile of PAH concentrations was consistent with soils that have undergone

107 extensive bioremediation (Bueno-Montes et al., 2011).

\subsection{Greenhouse experiments}

\subsubsection{Experimental design}

112 For this study, we used sunflower (Helianthus annuus L. cv. PR 63A90) seeds from the

113 University of California that were certified for agronomic crop production. The greenhouse

114 experimental design consisted of 5 pots with $2 \mathrm{~kg}$ of soil per treatment. The treatments included

115 uncontaminated soil planted with seeds (as a positive control for plant growth) and contaminated

116 soil with or without seeds. Five seeds were used per planted pot. The experiment was carried out

117 in a greenhouse at $23 \pm 1{ }^{\circ} \mathrm{C}$ and $20 \%$ field capacity. After 45 and 90 days, soil samples were

118 collected in each of three randomly chosen pots for each treatment for measurements of residual

119 PAH contents and microbiological determinations. Soil samples $(20 \mathrm{~g})$ were carefully extracted

120 from the rhizosphere zone with the aid of a glass tube $(150 \times 25 \mathrm{~mm})$ used as a bore. Care was

121 taken to avoid damaging the plants. Samples for the $\mathrm{PAH}$ analyses were stored at $-20^{\circ} \mathrm{C}$, and

122 samples for the microbiological analyses were stored at $4^{\circ} \mathrm{C}$. In both cases the samples were

123 analyzed separately. At the end of the experimental period, the percentage of germination was

124 evaluated for each treatment, and the fresh and dry weights of stems and roots were determined

125 separately. Dried stems and roots were generated by incubating the separated plant materials in a

126 desiccation oven $\left(70^{\circ} \mathrm{C}\right)$ for 72 hours.

\subsubsection{PAH Analysis}

129 Triplicate soil samples ( $1 \mathrm{~g}$ of soil per sample) from the initial polluted soil $(1: 1 \mathrm{w} / \mathrm{w})$ and

130 from the three pots with differet treatment at 45 days and 90 days after in the greenhouse

131 experiment, were dried completely using anhydrous sodium sulfate to grind the mixture in a

132 mortar and pestle. Samples were extracted in a Soxhlet with $100 \mathrm{~mL}$ dichloromethane for $8 \mathrm{~h}$.

133 Once the extract was obtained, the organic solvent was evaporated in a vacuum to nearly

134 complete dryness, and the residue was dissolved in $5 \mathrm{~mL}$ dichloromethane and cleaned by

135 passing through a Sep-Pak Fluorisil cartridge. The purified extracts were evaporated with $\mathrm{N}_{2}$, and 
136 the residues were dissolved in $2 \mathrm{~mL}$ of acetonitrile. Finally, the samples were filtered through a 137 nylon syringe filter $(0.45 \mu \mathrm{m}, 13 \mathrm{~mm} \varnothing$, Teknokroma, Barcelona, Spain). Quantification of PAHs

138 was performed using a Waters HPLC system (2690 separations module, 474 scanning

139 fluorescence detector, Nova-Pak $\mathrm{C}_{18}$ Waters PAH column, $5 \mu \mathrm{m}$ particle size and $4.6 \times 250 \mathrm{~mm}$,

$1401 \mathrm{~mL} \mathrm{~min}^{-1}$ flow and mobile phase with an acetonitrile-water gradient). The column was installed

141 in a thermostatic oven maintained at $30^{\circ} \mathrm{C}$.

\subsubsection{Autochthonous microbiota}

144

145

146

147

148

149

150

151

152

\subsubsection{Quantification of heterotrophic and hydrocarbon-degrading microbial populations}

Bacterial counts from triplicate soil samples were performed using the miniaturized most probable number (MPN) method in 96-well microtiter plates with 8 replicate wells per dilution (Wrenn and Venosa, 1996). Total heterotrophs were counted in diluted (1:10) Luria-Bertani medium; low molecular weight (LMW) PAH-degraders were counted in mineral medium (Grifoll et al., 1995) containing a mixture of phenanthrene $\left(0.5 \mathrm{~g} \mathrm{~L}^{-1}\right)$, fluorene, anthracene, and dibenzothiophene (each at a final concentration of $0.05 \mathrm{~g} \mathrm{~L}^{-1}$ ); and high molecular weight (HMW) PAH-degraders were counted in mineral medium containing pyrene at a final concentration of $0.5 \mathrm{~g} \mathrm{~L}^{-1}$. Hydrocarbon was added to the plates dissolved in pentane, and medium was added after solvent evaporation. MPN plates were incubated at room temperature $\left(25^{\circ} \mathrm{C} \pm 2^{\circ} \mathrm{C}\right)$ for 30 days. Positive wells were detected based on turbidity (heterotrophs) and observable coloration (brownish/yellow) for PAH degraders.

\subsubsection{DNA extraction and PCR amplification of eubacterial 16S rRNA genes}

Total DNA from soil and rhizosphere samples was extracted using a Power Soil DNA isolation kit (Mobio, Carlsbad, USA). Eubacterial 16S rRNA gene fragments were amplified from the extracted total DNA through PCR using pureTaq ${ }^{\mathrm{TM}}$ Ready-To-Go ${ }^{\mathrm{TM}}$ PCR bead tubes (GE healthcare, United Kingdom) in a final volume of $25 \mu \mathrm{L}$ containing $1 \mu 1$ of DNA extract as the template and 25 pmol of each primer (Sigma-Aldrich, Steinheim, Germany). To obtain clone libraries, we used the primers $27 \mathrm{f}$ and 1492r (Weisburg et al., 1991), and for the denaturing gradient gel electrophoresis (DGGE) fingerprinting analysis, we used GC40-63f and 518r. After 10 min of initial denaturation at $94^{\circ} \mathrm{C}, 30$ cycles of amplification were carried out, each consisting of $30 \mathrm{sec}$ of denaturation at $94^{\circ} \mathrm{C}, 30 \mathrm{sec}$ of annealing at $56^{\circ} \mathrm{C}$ and $1 \mathrm{~min}$ (DGGE) or 2 
166

167

168

169

170

171

172

173

174

175

176

177

178

179

180

181

182

183

184

185

186

187

188

189

190

191

192

193

194

195

196

min (clone libraries) of primer extension at $72^{\circ} \mathrm{C}$ followed by a final primer extension step of 10 min at $72^{\circ} \mathrm{C}$. All of the PCR amplifications were performed in an Eppendorf Mastercycler.

\subsubsection{DGGE analysis}

The 16S rRNA PCR amplification products were purified using the Wizard®SV Gel and PCR Clean-Up system (Promega, Madison, USA) and quantified in a NanoDrop®

Spectrophotometer ND-1000 prior to DGGE analysis. Identical amounts of PCR products were loaded in $6 \%$ polyacrylamide gels with denaturing gradients ranging from $45 \%$ to $70 \%$ (100\% denaturant contains $7 \mathrm{M}$ urea and $40 \%$ formamide). Electrophoresis was performed at a constant voltage of $100 \mathrm{~V}$ for $16 \mathrm{~h}$ in $1 \mathrm{x}$ TAE buffer ( $40 \mathrm{mM}$ Tris, $20 \mathrm{mM}$ sodium acetate, $1 \mathrm{mM}$ EDTA, pH 7.4) at $60^{\circ} \mathrm{C}$ in a DGGE-2001 System (CBS Scientific, Del Mar, CA, USA) machine. The gels were stained for 30 min with 1x SYBR Gold nucleic acid gel stain (Molecular Probes, Eugene, OR, USA) and photographed under UV light using a Bio-Rad molecular imager FX Pro Plus multi-imaging system (Bio-Rad Laboratories, Hercules, CA, USA) in the DNA stain gel mode for SYBRGold at medium sample intensity. DGGE bands were processed using Quantityone version 4.5.1 image analysis software (Bio-Rad Laboratories) and corrected manually.

\subsubsection{Construction, sequencing and phylogenetic analysis of $16 S r R N A$ gene clone libraries.}

Amplified 16S rRNA gene fragments were purified as described above and were cloned using the pGEM ${ }^{\circledR}-\mathrm{T}$ Easy Vector System (Promega, Madison, USA). Transformants were selected through PCR amplification using vector PCR primers. The PCR mixture contained 1.25 U of Taq DNA polymerase (Biotools B\&M Labs, Madrid, Spain), 25 pmol of each primer (Sigma-Aldrich, Steinheim, Germany), 5 nmol of each dNTP (Fermentas, Hanover, MD) and 1x PCR buffer (Biotools B\&M Labs) in a total volume of $25 \mu \mathrm{L}$. The obtained PCR products were purified, and inserts were sequenced using the ABI Prism Bigdye Terminator cycle-sequencing reaction kit (version 3.1) with the amplification primers $27 \mathrm{f}$ and $1492 \mathrm{r}$ and the internal primers $357 \mathrm{f}$ and 1087r (Lane, 1991). The sequencing reactions were performed using an ABI prism 3700 Applied Biosystems automated sequencer at Scientific-Technical Services of the University of Barcelona. DNA sequencing runs were assembled using BioEdit Software. Sequences were aligned using the BioEdit software package and manually adjusted. The resulting DNA sequence was examined and compared with BLAST alignment tool comparison software and the classifier tool of the 
197 Ribosomal Database Project II at http://rdp.cme.msu.edu/. The 16S rRNA gene sequences

198 obtained for the bacterial clones were deposited in the GenBank database with accession

199 numbers (JQ771957-JQ772014).

\subsection{Experiments with exudates}

\subsubsection{In vitro production}

204 In vitro production of sunflower root exudates was performed by placing 50 seeds in an inorganic salt solution (MM, pH 5.7) described elsewhere (Tejeda-Agredano et al., 2011). To avoid the introduction of alternative sources of organic carbon in the biodegradation experiments, the solution did not contain sucrose, vitamins or plant growth regulators. The medium was

208 prepared using ultrapure water (MILLIPORE). We transferred $500 \mathrm{~mL}$ of MM to glass jars

209 (1,000 mL capacity, $28 \times 11.5 \mathrm{~cm})$ previously sterilized for $20 \mathrm{~min} .\left(121^{\circ} \mathrm{C}, 1 \mathrm{~atm}\right.$. of pressure).

210 Inside these glass jars, we installed a square piece of stainless steel wire cloth $(0.98 \mathrm{~mm}$ light and

$2110.40 \mathrm{~mm}$ in diameter), held in place by four stainless steel wires extending from the edge of each

212 jar. The length of these wires was calculated such that the seeds on the mesh were in contact with

213 the surface of the MM without sinking into the solution to avoid producing anoxia. The jars were 214 closed firmly with a pressure system using a glass lid.

215 To sterilize the seeds, a batch of 50 seeds was surface-sterilized in $250 \mathrm{~mL}$ of absolute 216 ethanol for 3 minutes in sterilized Erlenmeyer flasks at $550 \mathrm{rpm}$. The ethanol was subsequently 217 removed, and $250 \mathrm{~mL}$ of a solution of $57 \%$ sodium hypochlorite (14\% active chlorine) was added 218 for $25 \mathrm{~min}$. Finally, the hypochlorite was eliminated, and the seeds were rinsed 3 times with 219 sterilized distilled water for 5 min each time, working in a laminar flow biosafety cabinet. Next, 220 the sterilized seeds were distributed on square cloth mesh. The size of the mesh allowed root 221 growth to occur and kept the seeds in place. The jar was closed, sealed with Parafilm and placed 222 in a culture room at $25 \pm 1^{\circ} \mathrm{C}, 65.24 \mu \mathrm{Em}^{-2} \mathrm{~s}^{-1}$ and with an 18 -hour photoperiod for 30 days. After 223 this period, the MM with the excreted exudates was collected under sterile conditions and 224 centrifuged for $3 \mathrm{~h}$ at $31,000 \mathrm{x} \mathrm{g}$ to obtain a solution that included the organic matter present, 225 removing the pellet as the method of Haftka et al., 2008. These samples were stored at $-20^{\circ} \mathrm{C}$ until 226 further use in the mineralization experiment. It is of particular note that the seeds were situated on 
the medium surface and never submerged such that only the developed roots were responsible for

228 exudate production.

229 In vitro exudate extraction was repeated 6 times, and at the end of each repetition, we

230 quantified the number of plants, determined the fresh and dry weight of the roots and assessed the

231 relative growth rate (RGR) of whole plants calculated according to the equation $\mathrm{RGR}=(\ln \mathrm{Bf}$ -

232 In $\mathrm{Bi}$ ) $\mathrm{D}^{-1}$ (Merckx et al., 1987), where Bf is the final dry biomass; Bi is the initial dry biomass

233 (average of 5 seedlings dried 3 days after germination of seeds); and D is the number of days of

234 the experiment. The plants acquired at the beginning and end of the greenhouse experiment were

235 dried by placing the plant material in the desiccation oven at $70^{\circ} \mathrm{C}$ for 72 hours.

\subsubsection{Chemical analyses of sunflower root exudates}

Total organic (TOC) and inorganic carbon estimations were carried out at IRNAS-CSIC based on measurements performed in a TOC Analyzer (TOC, model TOC-V CPH, Shimadzu, Japan) using a non-purgeable organic carbon (NPOC) analysis. The analyses of amino acids, organic acids and sugar were carried out at Scientific-Technical Services of the University of

242 Barcelona. Prior to analysis, the exudate sample was concentrated by freeze drying. The amino

243 acid content was analyzed through cationic exchange chromatography (Amino acids analyzer,

244 Biochrom 30, Biochrom, UK) and post-column derivatization with ninhydrin. The

245 chromatograph was equipped with a polysterene-divinylbenzene sulphonate column $(200 \mathrm{x} 4 \mathrm{~mm})$

246 with a $5 \mu \mathrm{m}$ film thickness. Elution was carried out using lithium citrate buffer with a $\mathrm{pH}$ and 247 ionic strength according to the manufacturer's instructions.

248 Low-molecular-weight organic acids were analyzed using a Water Alliance 2695

249 chromatograph coupled to a PE SCIEX API 365 triple quadruple mass spectrometer. The column

250 was an Aminex HPX-87H (300x7.8 mm) column (Bio-Rad, CA). The oven temperature was held

251 at $40^{\circ} \mathrm{C}$. The sample $(100 \mu \mathrm{L})$ was injected with a flow rate of $0.8 \mathrm{~mL} \mathrm{~min}^{-1}$ of water acidified

252 with acetic acid $(0.1 \%)$ and subjected to a post-column addition of methanol acidified in the same

253 manner. The analyses were performed using a Turbo Ion spray ionization source in negative

254 polarity with the following parameters: capillary voltage $-3500 \mathrm{~V}$, nebulizer gas $\left(\mathrm{N}_{2}\right) 10$

255 (arbitrary units), curtain gas $\left(\mathrm{N}_{2}\right) 12$ (arbitrary units), declustering potential $-60 \mathrm{~V}$, focusing

256 potential $-200 \mathrm{~V}$, entrance potential $10 \mathrm{~V}$. The drying gas $\left(\mathrm{N}_{2}\right)$ was heated to $350^{\circ} \mathrm{C}$ and 
257 introduced at a flow-rate of $7000 \mathrm{~mL} \mathrm{~min}^{-1}$. The results were analyzed in both Full Scan (40-400

$258 \mathrm{Da}$ ) and SIM (selected ion monitoring) modes.

259 The sugar content was analyzed in a Waters Alliance 2695 chromatograph equipped with 260 Aminex HPX-87P (300 x $7.8 \mathrm{~mm})$ and Aminex HPX-87C (300 x $7.8 \mathrm{~mm})$ columns (BioRad,

261 CA) connected to a refraction index detector (Waters 2414 ) at a temperature of $37^{\circ} \mathrm{C}$. The solvent 262 system consisted of purified water at a flow rate of $0.6 \mathrm{~mL} \mathrm{~min}^{-1}$. The oven temperature was held 263 at $85^{\circ} \mathrm{C}$.

264 Aromatic carboxylic acids and fatty acids were detected using GC-MS analysis based on 265 methylated derivatives. After acidification with $1 \mathrm{M} \mathrm{HCl}(\mathrm{pH} 2), 50 \mathrm{~mL}$ of the exudates was 266 extracted with ethyl acetate $(5 \times 20 \mathrm{~mL})$, and the extracts were concentrated under vacuum to 1 $267 \mathrm{~mL}$ and derivatized via treatment with ethereal diazomethane. Analyses were performed on a 268 Hewlett Packard HP5890 Series II gas chromatograph coupled to an HP 5989 mass spectrometer 269 using a DB5 (J\&W Scientific, Folsom, CA) capillary column (30 x $0.25 \mathrm{~mm}$ i.d.) with a $0.25-\mu \mathrm{m}$ 270 film thickness. The column temperature was held at $50^{\circ} \mathrm{C}$ for $1 \mathrm{~min}$ and increased to $310^{\circ} \mathrm{C}$ at $27110^{\circ} \mathrm{C} \mathrm{min}^{-1}$, and this final temperature was maintained for $10 \mathrm{~min}$. The mass spectrometer was 272 operated at a $70 \mathrm{eV}$ electron ionization energy. The injector and analyzer temperatures were set at $273290^{\circ} \mathrm{C}$ and $315^{\circ} \mathrm{C}$, respectively. The samples $(1 \mu \mathrm{L})$ were injected in splitless mode using helium 274 as the carrier gas at a flow rate of $1.1 \mathrm{~mL} \mathrm{~min}^{-1}$. When possible, products were identified and 275 quantified through comparison of their MS spectra and GC retention times with those obtained 276 for authentic commercial standards. When authentic products were not available, identification 277 was suggested on the basis of data in databases (National Institute of Standards and Technology).

\subsubsection{Bioaccessibility experiments with exudates}

280 The bioaccessibility estimations relied on the determination of residual concentrations of 281 native PAHs when ${ }^{14} \mathrm{C}$-tracer biodegradation decreased in radiorespirometry assays performed in 282 parallel (Bueno-Montes et al., 2011). To measure pyrene mineralization by indigenous bacteria in 283 the presence or absence of sunflower root exudates, $1 \mathrm{~g}$ of soil was suspended in $70 \mathrm{~mL}$ of MM 284 or sunflower root exudates. The suspensions were placed in $250 \mathrm{~mL}$ Erlenmeyer flasks under 285 sterile conditions, and each treatment was performed in duplicate. Each of the flasks contained $28630000 \mathrm{dpm}$ of radiolabeled pyrene $\left(58.7 \mathrm{mCi} \cdot \mathrm{mmol}^{-1}\right.$, radiochemical purity $\left.>98 \%\right)$ in $1 \mathrm{~mL}$ of 287 MM. The flasks were sealed with Teflon-lined stoppers and were maintained at $25^{\circ} \mathrm{C}$ on a rotary 
288 shaker operating at $80 \mathrm{rpm}$. The production of ${ }^{14} \mathrm{CO}_{2}$ was measured as the radioactivity appearing 289 in an alkali trap. The trap consisted of a $5 \mathrm{~mL}$ vial suspended from the Teflon-lined stopper; the 290 vial contained $1 \mathrm{~mL}$ of $\mathrm{NaOH}(0.5 \mathrm{M})$. Periodically, the solution was removed from the trap and 291 replaced with fresh alkali. The $\mathrm{NaOH}$ solution was mixed with $5 \mathrm{ml}$ of a liquid scintillation 292 cocktail (Ready Safe; Beckman Instruments), and the mixture was maintained in darkness for 293 approximately $8 \mathrm{~h}$ to allow dissipation of chemiluminescence. Radioactivity was then measured 294 with a liquid scintillation counter (model LS5000TD; Beckman Instruments).

295 To determine the biodegradation of the native PAHs present in the soil, separate duplicate 296 flasks (with and without exudates) were incubated under the same conditions, but without 297 addition of the ${ }^{14} \mathrm{C}$-labeled compound. At the end of the incubation period $(250 \mathrm{~h})$, extraction and 298 analysis of the PAHs present in the soil mixture suspension were conducted by Soxhlet and then 299 by HPLC (residual contents in aqueous phase are under the detection limit) by the same method 300 as described in section 2.2.2. Analysis of microbial communities from cultures with and without 301 exudates was performed as described previously in sections 2.2.3.2. and 2.2.3.3.

\subsection{Statistical methods}

304 Analysis of variance (ANOVA) and Tukey honest significant differences (HDS) were used to 305 assess the significance of means, and Student's t-test was used to determine the significance of 306 percentages. These statistical analyses were performed using SPSS v. 19 software. Differences obtained at the $p \leq 0.05$ level were considered to be significant.

\section{Results}

\section{3.1. Greenhouse experiment}

\subsubsection{Plant response}

All of the sunflower seeds germinated in both contaminated and uncontaminated soils within

31515 days of the beginning of the experiment. However, after 90 days, the average stem height (67 $316 \mathrm{~cm})$ and dry weight of whole plants $(6.51 \mathrm{~g})$ were significantly higher $(\mathrm{p} \leq 0.05)$ in plants grown in 317 contaminated soil than in those developing in uncontaminated soil $(57.9 \mathrm{~cm}$ and $4.46 \mathrm{~g}$, 318 respectively). These differences may be related to the autoclaving procedure used for the 
319 uncontaminated soil. The activity of microorganisms introduced into the soil mixture with the 320 creosote-polluted soil may have been beneficial for the plants due to detoxifying contaminants 321 and mobilizing soil nutrients. Therefore, the good development of plants in contaminated soil is 322 an indirect indicator of the origin of the microbial populations developed during the greenhouse 323 experiment.

\subsubsection{Dissipation of PAHs in pots with polluted soil}

Measurement of residual PAH concentrations showed the promoting effect of planting $H$. annuus on the dissipation of these chemicals from soil (Table 1). The concentrations of

328 anthracene, fluoranthene, pyrene and crysene in planted soils decreased significantly below the

329 levels detected in the unplanted controls after 45 and $90 \mathrm{~d}$. A positive effect of planting on the

330 dissipation of fluorene was only observed after $45 \mathrm{~d}$, and its concentration remained below the

331 detection limit in both planted and unplanted soils after 90 days. The presence of sunflower

332 plants had no significant effect on the dissipation of phenanthrene in any of the sampling periods.

333 The absence of effect may be connected to the higher solubility in water of this compound (1.8

$\left.334 \mathrm{mg} \mathrm{L}^{-1}\right)$, as compared with anthracene $\left(0.045 \mathrm{mg} \mathrm{L}^{-1}\right)$, fluoranthene $\left(0.206 \mathrm{mg} \mathrm{L}^{-1}\right)$, pyrene $(0.13$

$\left.335 \mathrm{mg} \mathrm{L}^{-1}\right)$ and chrysene $\left(1.8 \cdot 10^{-3} \mathrm{mg} \mathrm{L}^{-1}\right)$, what may have caused less bioavailability restrictions to

336 biodegradation of phenanthrene. The increased dissipation was reflected in the significantly

337 lower $(\mathrm{P} \leq 0.05)$ concentration of total PAHs in planted pots compared to the unplanted controls,

338 which resulted in a $60 \%$ additional decrease in the total PAH content in both sampling periods.

339 With the exception of fluorene, extending the experimental period to 90 days did not result in a

340 significantly lower residual concentration of any of the PAHs in the soils. The chemical analysis

341 of major soil characteristics (e.g., $\mathrm{pH}$, texture) did not reveal significant differences after planting

342 with sunflowers, with the only difference being found in the content of total organic carbon,

343 which increased in the planted soils from 0.9 to $2.1 \%$ after 90 days.

\subsubsection{Analysis of the autochthonous microbiota and its population dynamics}

346 Microbial counts indicated that the soil used in this study was highly enriched in PAH

347 degraders (Fig. 1). The heterotrophic microbial populations increased more than two orders of

348 magnitude between days 0 and 45 under all the conditions. The treatments with plants did not

349 seem to produce an additional enhancement of the growth of the heterotrophs in comparison to 
350 the untreated soil. These populations decreased slightly between days 45 and 90, except in the 351 treatment with plants, where they remained at similar levels. This finding could be explained by 352 general depletion of the available carbon sources, which would be compensated for by the 353 rhizosphere in the plant treatment. The LMW PAH-degrading populations also increased in size 354 by approximately two orders of magnitude between 0 and 45 days under all conditions but 355 decreased thereafter in the control soil, while remaining approximately constant in the plant 356 treatment. Interestingly, HMW PAH degraders experienced a substantial increase by $45 \mathrm{~d}$, 357 especially in the plant treatment, and remained at high levels until the end of the experiment. 358 Because at 90 days, the ratio between the HMW PAH degraders and total heterotrophic 359 populations was substantially higher in the treated than in the untreated soil, it could be 360 concluded that in addition to stimulating the general growth of the heterotrophic populations 361 (including that of PAH degraders), the rhizosphere treatment had an additional selective effect of 362 enhancing the growth of the HMW PAH-degrading populations. In addition, these results show 363 that an increase in microbial growth can be obtained by supplementing soil with carbon sources 364 and nutrients (present in exudates) and by improving the biodegradation of PAHs, possibly by 365 increasing their bioaccessibility.

366 It is known that the microbial communities in the rhizosphere can be considerably different 367 than those in nearby soil that grow without the direct influence of roots. As a first step in 368 understanding whether the increase in PAH degradation observed in the treated soil containing 369 plants could be related to specific changes in the microbial community structure, we used DGGE 370 and clone library analysis. The DGGE fingerprints obtained during the incubation period from 371 replicate samples for each treatment showed very similar banding profiles (Fig. 2), indicating 372 strong homogeneity within the pots for each condition. In general, the DGGE analysis revealed 373 an initially diverse microbial community, with specific populations increasing in relative 374 abundance throughout the incubation period in both the non-treated and the rhizosphere soil. A 375 number of the bands obtained coincided in the two treatments, but their relative intensities 376 differed, indicating that the shift in community structure induced by the rhizosphere was different 377 than that induced by the simple potting and watering of the polluted soil.

378 To gain insight into which microbial groups were selectively promoted by the rhizosphere in 379 comparison to the non-treated soil, corresponding 16S rRNA gene libraries were obtained from 380 samples taken at 90 days, and a total of 84 clones were analyzed. Table 2 indicates the relative 
381 abundance and phylogenetic affiliation of each of the eubacterial populations detected, while Fig.

3823 summarizes the importance of the different bacterial phyla in the non-treated and sunflower 383 rhizosphere soils. Approximately two-thirds (60 and 68\%) of the bacteria detected under both 384 conditions belonged to the $\alpha-, \beta$-, and $\gamma$-Proteobacteria, Actinobacteria, Bacteroidetes, and 385 Chloroflexi phyla. However, with the exception of the Actinobacteria, the relative abundances of 386 these phyla and their compositions varied substantially with the treatment applied, confirming 387 that the plants caused a dramatic shift in the community structure. The rhizosphere promoted the 388 appearance of new populations within the three Proteobacteria subphyla, including 389 representatives with a well-known capacity to degrade PAHs (Kanaly and Harayama, 2010). 390 Within the $\alpha$-Proteobacteria, the increase of the Sphingomonas group was interesting because 391 this group included numerous members isolated from plant root systems and members with a 392 versatile degrading capability allowing them to attack 2-, 3- and 4-ring PAHs (Fernández393 Luqueño et al., 2011). There was also a noticeable increase in the $\beta$-Proteobacteria (from $9 \%$ to 394 27\%), as the rhizosphere promoted the appearance of members of the Commamonas group 395 showing high similarity matches to members in the database isolated from PAH-contaminated 396 soil or xenobiotic degraders (i.e., Variovorax).

397 In the non-planted soil, $40 \%$ of the detected microorganisms belonged to seven phylogenetic 398 groups not detected in the sunflower planted soil. Interestingly, among these microbes, we found members of the Candidate divisions OD1, OP11, TM7 and WS6, which are lineages of 403 retrieved from non-treated soil revealed a relatively high abundance of Firmicutes, while the 404 Planctomycetes and Deinococcus groups were represented with lower proportions. In contrast, 405 the sunflower rhizosphere soil promoted the presence of four phylotypes (Acidobacteria, 406 Gemmatimonadetes, $\delta$-Proteobacteria and Cyanobacteria) that were not detected in the non407 treated soil. The most abundant, the Acidobacteria (14.6\%) and Gemmatimonadetes (7.3\%), 408 constitute recently described new phyla (Ludwig et al., 1997; Zhang et al., 2003) and are broadly 409 distributed in soils but poorly represented in cultures, which makes it difficult to ascertain their 410 role in nature. The Acidobacteria have been observed previously in planted soil (Yrjala et al., 411 2010), are usually found in non-polluted environments, and generally decrease in the presence of 
412 pollutants. Therefore, their higher abundance here after 90 days of treatment may be explained by

413 both the rhizosphere effect and the high degree of removal of PAHs attained in this condition.

\subsection{In vitro production of exudates}

\subsubsection{Production}

After 30 days, the average of germination rate was $55.33 \%$, with the growth per day in terms

419 of weight being $74 \mathrm{mg}$. The average fresh and dry weights of roots were 12.04 and $0.965 \mathrm{~g}$,

420 respectively, and the levels of TOC produced by the exudates were between 54.4 and $339 \mathrm{mgL}^{-1}$, 421 with an average of $129.73 \mathrm{mg} \mathrm{L}^{-1}$. A direct significant linear correlation $(\mathrm{R}=0.9125)(\mathrm{p} \leq 0.05)$ was 422 established between the RGR (74 mg per day) and fresh weight (12.04 g). There was also a direct 423 linear correlation found between TOC (129.73 $\left.\mathrm{mg} \mathrm{L}^{-1}\right)$ with RGR $(\mathrm{R}=0.7293)$ and TOC with

424 fresh weight $(\mathrm{R}=0.6366)$, although these correlations were not statistically significant.

\subsubsection{Exudate Composition}

Table 3 shows the compounds identified in the sunflower root exudates using different analytical techniques, including carbohydrates, amino acids, fatty acids, aromatic acids and certain secondary metabolites. As major carbohydrates, we identified fructose (2.44 ppm) and galactose (1.16 ppm); however, the chromatogram also showed a major unidentified peak that

431 would have interfered with the detection of glucose if it had been present. Previous studies

432 addressing exudate composition in tomato, sweet pepper, cucumber and Barmultra grass showed

433 that fructose was one of most dominant sugars (Kuiper et al., 2002; Kamilova et al., 2006).

434 Galactose is also present in root exudates, providing a favorable environment for the growth of 435 microorganisms (Bertin et al., 2003), and has been detected in the root exudates of different 436 species of Eucalyptus (Grayston et al., 1996). Amino acids were detected in a wide range of 437 concentrations, among which asparagine $(0.593 \mathrm{ppm})$ and glutamine $(0.301 \mathrm{ppm})$ were the most 438 abundant, while methionine, tryptophan, proline, glutamic acid and valine were not detected.

439 Phosphoethanolamine was also detected at a relatively high concentration (0.571 ppm) and has 440 been reported to be abundant in the cell membrane (Ofosubudu et al., 1990). The main fatty acids 441 present were palmitic and estearic acids, whereas others, including the most abundant component 442 of sunflower oil, linoleic acid, were detected at lower concentrations and could not be quantified. 
443 Several aromatic acids were identified, the most abundant of which were phthalic and

444 protocatechuic acids. This result is of particular note, given that these compounds are typical

445 intermediates in the metabolism of PAHs by bacteria (Kanaly and Harayama, 2010). The HPLC-

446 MS analysis of organic acids revealed several products. The most intense signal corresponded to

447 a compound with a mass compatible with gluconic acid. Other products were tentatively

448 identified as caffeic, isocitric, butiric, pyruvic, propionic, fumaric, malic, and malonic acids, all

449 of which are typically found in root exudates (Bertin et al., 2003). Abietic acid and the

450 sesquiterpene tomentosin were identified as the methyl derivatives of organic acids in the GC-MS

451 analysis, and in addition to having structures analogous to some PAHs, they exhibit different

452 functions in the plant-microbe interaction.

453 In vitro, the sunflower root exudates showed a surface tension close to the surface tension of 454 the mineralization medium (MM), showing either an absence or a low concentration of 455 surfactants that could improve accessibility.

\subsubsection{Effects of exudates on the bioaccessibility of PAHs and on soil microbial populations}

Bioaccessibility experiments showed that the maximum rate of pyrene mineralization was

460 enhanced twofold by the presence of exudates (from $0.024 \pm 0.002 \mathrm{ng} \mathrm{mL}^{-1} \mathrm{~h}^{-1}$ to $0.052 \pm 0.008$

$461 \mathrm{ng} \mathrm{mL} \mathrm{m}^{-1} \mathrm{~h}^{-1}$, Figure 4). The maximum extent of pyrene $\mathrm{C}$ mineralization was also enhanced (from

$46229 \pm 1.01 \%$ to $40 \pm 1.41 \%$ ), and the acclimation phase for pyrene mineralization was shortened

463 from $75 \mathrm{~h}$ to $30 \mathrm{~h}$. Interestingly, the results showed that the concentrations of total PAHs

464 decreased to significantly lower values in the presence of exudates (Table 4), thereby

465 demonstrating the positive influence of exudates on biodegradation for native chemicals.

466 Furthermore, the residual contents of total PAHs, both with and without exudates, were not

467 significantly different than those reached in the corresponding treatments in greenhouse

468 experiments after 90 days $(P \leq 0.05)$. Therefore, we can conclude that the degradation-promoting

469 effect of sunflower plants on the dissipation of PAHs from soil that occurred in the greenhouse

470 experiment could be reproduced through laboratory incubation of the soil with shaking and the

471 addition of root exudates. The shorter time period needed in the slurries to reach residual

472 concentrations (10 days), as compared to greenhouse conditions (90 days), can be attributed to an

473 enhanced mass transfer of the pollutants. However, because the controls and the exudate- 
containing slurries were treated exactly in the same way, the observed relative differences still suggest an effect of root exudates on bioaccessibility.

Soil suspensions were sampled at the end of the experimental period $(10 \mathrm{~d})$ to determine the evolution of autochthonous microbiota using DGGE (Fig. 5). The DGGE profiles from cultures in the mineral medium with or without exudates indicated an increase in the number of microorganisms during the 10 days of the experiment in both conditions. In the absence of exudates, duplicate cultures showed similar banding profiles with slight differences in the relative intensity of each band. The banding profile changed as a result of exposure to exudates, which indicates that the enhanced PAH degradation was accompanied by the growth of specific microbial populations.

\section{Discussion}

Our data indicate that the development of sunflower plants enhanced the biodegradation of PAHs in the soil, and due to the ability of microbes to reduce the phytotoxicity of the pollutants, PAHs included, sunflower plants were able to grow in polluted soil even better than those grown in uncontaminated soil. The slowly degrading compounds remaining in the soil at the end of greenhouse and bioaccessibility assays probably exhibited slow desorption, which usually limits biodegradation of these compounds by microorganisms (Bueno-Montes et al., 2011). This restriction on biodegradation would explain the absence of further decreases in the PAH concentrations in unplanted soils from $45 \mathrm{~d}$ to $90 \mathrm{~d}$ in the greenhouse experiment and the good agreement between the residual PAH concentrations in the greenhouse and bioaccessibility assays. The bioaccessibility experiments were designed to test the disappearance of the chemicals under laboratory conditions. These assays specifically addressed biodegradation using an excess of nutrients, radiorespirometry determinations with ${ }^{14} \mathrm{C}$-pyrene and analysis of residual concentrations of native PAHs. This method had been applied previously to determine the efficiency of bioremediation approaches designed to increase the bioaccessibility of aged PAHs (Bueno-Montes et al., 2011). Despite the inherent difficulties in performing bioaccessibility estimations related to the specific the time period and/or target organisms considered (Alexander, 2000), this approach was very useful in the present study for reproducing the greenhouse results in the presence of root exudates produced in vitro, which indicates that the exudates played an 
505 important role in the effectiveness of the plants in promoting the bioaccessibility of PAHs. To our

506 knowledge, the direct comparison of pollutant losses in the presence of plants with those caused

507 by the addition of exudates had not been included in previous studies of PAH rhizoremediation.

508 The TOC content observed in the sunflower root extracts in this study, $129.73 \mathrm{mg} \mathrm{L}^{-1}$, was in 509 agreement with TOC values reported in other studies on the promoting effects of root extracts on 510 PAH-degrading microorganisms. For example, Rentz et al. (2005) reported TOC concentrations

511 of 84.2, 175.0 and $51.7 \mathrm{mg} \mathrm{L}^{-1}$ from root extracts of hybrid willow (Salix alba x matsudana), kou

512 (Cordia subcordata) and milo (Thespesia populnea), respectively, whereas Miya and Firestone

513 (2001) reported a TOC concentration of $54 \mathrm{mg} \mathrm{L}^{-1}$ for slender oat root exudates. In the present

514 study, it is possible that the organic carbon in the exudates enhanced the bioaccessibility of PAHs

515 through a mechanism related to the carbon's capacity to mobilize PAHs that are initially

516 absorbed in the soil. Indeed, addition of DOM to contaminated soils results in enhanced

517 biodegradation of PAHs, probably as a result of enhanced desorption (Bengtsson and Zerhouni,

518 2003). DOM-mediated enhancement of biodegradation can also be caused by direct access to

519 DOM-sorbed PAHs due to the physical association of bacteria and DOM (Ortega-Calvo and

520 Saiz-Jimenez, 1998) and an increased diffusive flux toward bacterial cells (Haftka et al., 2008;

521 Smith et al., 2009). The latter mechanism would be analogous to that described for the enhanced

522 uptake of metals by plants in the presence of labile metal complexes, which is caused by an

523 increased diffusional flux through unstirred boundary layers around roots (Degryse et al., 2006).

524 The occurrence of DOM-mediated enhancement of bioaccessibility through root exudation would 525 also explain the greater extent of biodegradation observed under greenhouse conditions, despite 526 the significant increase of total organic carbon in the planted soils.

527 The chemical characterization of exudates also identified specific substances with the 528 potential to directly enhance bioaccessibility. These substances include chemicals that are able to

529 induce chemotaxis, which constitutes a relevant mobilization mechanism for motile

530 microorganisms in the soil (Ortega-Calvo et al., 2003). For example, sugars such as fructose have

531 a well-known positive chemotactic effect on soil microorganisms. Amino acids, such as

532 glutamine, aspartic acid and isoleucine, which were also found in this study as components of

533 sunflower root exudates, are powerful chemoattractants for Rhizobium and Bradyrhizobium

534 japonicum (Pandya et al., 1999). Zheng and Sinclair (1996) indicated that alanine, asparagine,

535 glutamine, serine, and threonine in soybean root exudates may serve as chemoattractants to 
536 Bacillus megaterium strain B153-2-2. Finally, we detected fatty acids, such as palmitic acid and

537 stearic acid, which are plant components with a known potential to enhance the bioaccessibility

538 of PAHs in soil by acting as surfactants (Yi and Crowley, 2007). Vegetable oils have also been

539 widely used as natural surfactants (Gong et al., 2010), resulting in the dissolution of PAHs and

540 consequently, in the enhancement of biodegradation. Therefore, the presence of these compounds

541 may explain the greater decrease in PAHs observed in the sunflower soil treatments.

542 Furthermore, it is also possible that the preferential growth of rhizosphere microorganisms

543 observed on the exudate components at specific sites inside soil aggregates may have caused

544 colony growth in the vicinity of pollutant sources and may have modified the structure of the soil

545 aggregates to promote bioaccessibility through the excretion of extracellular polymeric

546 substances and biosurfactants.

547 Therefore, the results obtained associated with root exudates indicated a role for promoting

548 the bioaccessibility of PAHs. However, the present study may not allow complete discrimination

549 between the effects on bioaccessibility from the enhanced biodegradation activity of

550 microorganisms caused by the chemical components of exudates. The evolution of the

551 heterotrophic bacterial population in the soil during the greenhouse experiment indicates that

552 homogenization, aeration and watering had a general activation effect on this population, but

553 planting sunflowers had a further positive impact due to maintaining their viability (Fig. 1). The

554 chemical analysis of exudates reflected the presence of organic compounds in the root exudates

555 with the potential to cause this effect. For example, fructose and galactose are known to provide a

556 favorable environment for the growth of rhizosphere microorganisms (Grayston et al., 1996;

557 Bertin et al., 2003); amino acids are a source of easily degradable N compounds, inducing

558 protease synthesis (García-Gil et al., 2004); and ornithine is considered to be non-protein amino

559 acids showing a protective function against stress to cell membranes (Kalamaki et al., 2009).

560 Furthermore, the presence of plants had also a profound impact on the relative abundance of

561 specific groups of bacteria in the soil, thereby increasing their biodiversity. This consideration is

562 consistent with the results obtained in the PAH analysis and confirm the results obtained by other

563 authors (Miya and Firestone, 2000; Parrish et al., 2005). The proportion of gram-negative

564 bacteria increased in planted soils compared with unplanted controls, which is in agreement with

565 previous observations (Anderson and Coats, 1995). For example, we observed better

566 development of $\beta$-Proteobacteria in planted soils, which can be explained by the capability of 
567 this group of bacteria to readily assimilate the $\mathrm{C}$ present in sugars and residues of plant origin

568 (Bernard et al., 2007). In the same way, the rhizophere promoted the appearance of members of

569 the Oxalobacteriaceae, a recently described but uncharacterized family with root colonizing

570 members (Green et al., 2007) that are closely related to the Burkholderia, which include

571 important soil PAH degraders of both single compounds and creosote mixtures (Grifoll et al.,

572 1995). The increase observed in members of the Methylophillus group was interesting because in

573 a recent study, a methylotrophic bacterial species was identified as one of the most abundant

574 components of a heavy fuel-degrading consortium (Vila et al., 2010). Methylotrophic bacteria are

575 more widely distributed than previously thought, but their roles in natural habitats remain

576 unknown (Lidstrom, 2006; Chistoserdova et al., 2009). The Xanthomonas group within the $\gamma$ -

577 Proteobacteria was also favored by the rhizosphere, with several of the detected representatives

578 of this group corresponding to bacteria previously detected in polluted sites and identified as

579 PAH degraders. For example, a Pseudoxhantomonas strain was recently described as being able

580 to degrade the 4-ring PAH chrysene (Nayak et al., 2011). The reduction in the abundance of

581 Bacteroidetes in the rhizosphere soil could be a direct consequence of the presence of nutrients

582 from the exudates because this phylum has often been associated with non-nutrient environments

583 (Viñas et al., 2005).

$584 \quad$ Interestingly, certain aromatic organic acids were detected in the root exudates, such as

585 phthalic and protocatecuic acids, that are intermediate metabolites in the degradation of PAHs

586 (Lopez et al., 2008). These secondary plant metabolites may stimulate PAH degradation by

587 rhizosphere microorganisms and broaden the spectrum of their activity by inducing and

588 promoting the development of organic pollutant-degrading enzymes or acting as cosubstrates in

589 cometabolic reactions. Indeed, the population of high-molecular-weight (HMW) PAH degraders

590 increased in number in the planted soils compared with the unplanted controls, demonstrating the

591 selective influence of the sunflower rhizosphere on these populations. These results agree with

592 those from Parrish et al. (2005), who observed that after 12 months of plant development, the

593 PAH degrader population was multiplied 100-fold in comparison with unplanted soil. Corgie et

594 al. (2004) also found that the number of HMW PAH degraders decreased inversely with the

595 distance from roots. Consistent with this selective effect on the PAH-degrading populations, there

596 was a demonstrated increase in the relative abundance of bacterial groups with a know PAH-

597 degrading capability or that were previously detected as key components in PAH-degrading 
598 microbial consortia, including Sphingomonas (within the $\alpha$-Proteobacteria), Comamonas,

599 Oxalobacteria and Methylophillus ( $\beta$-Proteobacteria), and Xanthomonas (Kanaly and Harayama,

600 2010). Although the relative abundance of the Actinobacteria group does not change in the

601 presence of sunflowers, it is known that this a group characterized by its ability to degrade

602 recalcitrant organic compounds. Other microbes that are able to degrade recalcitrant organic

603 compounds include Actinomycetes, which are able to compete with fungi for lignin degradation,

604 and Mycobacteria, which can degrade a variety of PAHs either as individual compounds or

605 within fuel (Vila et al., 2010) and creosote mixtures (López et al., 2008), particularly at sites

606 where there is a low level of nutrients. Other bacterial phyla favored by the rhizosphere,

607 including Acidobacteria and the Gemmatimonadetes, are recently described groups with few

608 culturable representatives, and more research is needed to understand their potential role in

609 polluted soils (Ludwig et al., 1997; Zhang et al., 2003).

610 Considering the advantages of this plant species in relation to its agronomic interest and

611 potential as a biofuel producer, this strategy represents a promising alternative for increasing

612 bioaccessibility in a sustainable and low-risk manner. Our results demonstrate that the

613 rhizosphere caused a substantial shift in the structure of the autochthonous microbial populations

614 in the soil that selectively favored the development of PAH degraders. Most of the literature

615 discussed herein involves recent work on the effect of the rhizosphere on selected microbial

616 PAH-degrading populations in artificially PAH-spiked soils. This study is the first to analyze the

617 effect of the rhizosphere on autochthonous bacterial community structure from a real PAH-

618 polluted soil. The exact contribution of the direct effects of the sunflower exudates and the effects

619 related to the ecology of soil microorganisms will be the subject of future research.

620

\section{Acknowledgments}

622 Support for this research was provided by the Spanish Ministry of the Economy and 623 Competitiveness (grants CGL2007-64199, CGL2010-22068-C02-01 and CGL2010-22068-C02624 02) and the FPI Programme (M.C. Tejeda-Agredano) and FPU Programme (S. Gallego), M. 625 Grifoll and J. Vila are members of the Xarxa de Referència de R+D+I en Biotecnologia (XRB), 626 wich receives funding from the Generalitat de Catalunya. 


\section{References}

Alexander, M., 2000. Aging, bioavailability, and overestimation of risk from environmental pollutants. Environmental Science and Technology, pp. 4259-4265.

Anderson, T.A., Coats, J.R., 1995. An overview of microbial degradation in the rhizosphere and its implications for bioremediation, Bioremediation: Science and Applications, pp. 135-143.

Bengtsson, G., Zerhouni, P., 2003. Effects of carbon substrate enrichment and DOC concentration on biodegradation of PAHs in soil. Journal of Applied Microbiology 94, 608-617.

Bernard, L., Mougel, C., Maron, P.A., Nowak, V., Leveque, J., Henault, C., Haichar, F.e.Z., Berge, O., Marol, C., Balesdent, J., Gibiat, F., Lemanceau, P., Ranjard, L., 2007. Dynamics and identification of soil microbial populations actively assimilating carbon from C-13-labelled wheat residue as estimated by DNA- and RNA-SIP techniques. Environmental Microbiology 9, 752764.

Bertin, C., Yang, X.H., Weston, L.A., 2003. The role of root exudates and allelochemicals in the rhizosphere. Plant and Soil 256, 67-83.

Bueno-Montes, M., Springael, D., Ortega-Calvo, J.J., 2011. Effect of a non-ionic surfactant on biodegradation of slowly desorbing PAHs in contaminated soils. Environmental Science and Technology 45, 3019-3026.

Corgie, S.C., Beguiristain, T., Leyval, C., 2004. Spatial distribution of bacterial communities and phenanthrene degradation in the rhizosphere of Lolium perenne L. Applied and Environmental Microbiology 70, 3552-3557.

Chistoserdova, L., Kalyuzhnaya, M.G., Lidstrom, M.E., 2009. The Expanding World of Methylotrophic Metabolism, Annual Review of Microbiology, pp. 477-499.

Chouari, R., Le Paslier, D., Dauga, C., Daegelen, P., Weissenbach, J., Sghir, A., 2005. Novel major bacterial candidate division within a municipal anaerobic sludge digester. Applied and Environmental Microbiology 71, 2145-2153.

Degryse, F., Smolders, E.,Merckx, R., 2006. Labile Cd Complexes Increase Cd Availability to Plants. Environmental Science and Technology 40, 830-836.

Fernández-Luqueño, F., Valenzuela-Encinas, C., Marsch, R., Martínez-Suarez, C., VázquezNúñez, E., Dendooven, L., 2011. Microbial communities to mitigate contamination of PAHs in soil-possibilities and challenges: a review. Environmental Science and Pollution Research 18, 1230 .

García-Gil, J.C., Plaza, C., Senesi, N., Brunetti, G., Polo, A., 2004. Effects of sewage sludge amendment on humic acids and microbiological properties of a semiarid Mediterranean soil. Biology and Fertility of Soils 39, 320-328. 
Gong, Z.Q., Wang, X.G., Tu, Y., Wu, J.B., Sun, Y.F., Li, P., 2010. Polycyclic aromatic hydrocarbon removal from contaminated soils using fatty acid methyl esters. Chemosphere 79, 138-143.

Grayston, S.J., Vaughan, D., Jones, D., 1996. Rhizosphere carbon flow in trees, in comparison with annual plants: the importance of root exudation and its impact on microbial activity and nutrient availability. Applied Soil Ecology 5, 29-56.

Green, S.J., Michel, F.C., Hadar, Y., Minz, D., 2007. Contrasting patterns of seed and root colonization by bacteria from the genus Chryseobacterium and from the family Oxalobacteraceae. Isme Journal 1, 291-299.

Grifoll, M., Selifonov, S.A., Gatlin, C.V., Chapman, P.J., 1995. Actions of a versatile fluorenedegrading bacterial isolate on polycyclic aromatic-compounds. Applied and Environmental Microbiology 61, 3711-3723.

Hao, L.H., He, P.Q., Liu, C.Y., Chen, K.S., Li, G.Y., 2004. Physiological effects of taurine on the growth of wheat (Triticum aestivum L.) seedlings. J Plant Physiol Mol Biol. 30:595-598.

Haftka, J.J.H., Parsons, J.R., Govers, H.A.J., Ortega-Calvo, J.J., 2008. Enhanced kinetics of solid-phase microextraction and biodegradation of polycyclic aromatic hydrocarbons in the presence of dissolved organic matter. Environmental Toxicology and Chemistry 27, 1526-1532.

Kalamaki, M.S., Merkouropoulos, G., Kanellis, A.K., 2009. Can ornithine accumulation modulate abiotic stress tolerance in Arabidopsis? Plant Signal Behav 4:1099-1101.

Kamilova, F., Kravchenko, L.V., Shaposhnikov, A.I., Azarova, T., Makarova, N., Lugtenberg, B., 2006. Organic acids, sugars, and L-tryptophane in exudates of vegetables growing on stonewool and their effects on activities of rhizosphere bacteria. Molecular Plant-Microbe Interactions 19, 250-256.

Kanaly, R.A.,Harayama, S., 2010. Advances in the field of high-molecular-weight polycyclic aromatic hydrocarbon biodegradation by bacteria. Microbial Biotechnology 3, 136-164.

Kuiper, I., Kravchenko, L.V., Bloemberg, G.V., Lugtenberg, B.J.J., 2002. Pseudomonas putida strain PCL1444, selected for efficient root colonization and naphtalene degradation, effectively utilizes root exudate components. Molecular Plant-Microbe Interactions 15, 734-741.

Lane, D. J., 1991. 16S/23S rRNA sequencing, p. 115-175. In E. Stackebrandt and M. Goodfellow (ed.), Nucleic acid techniques in bacterial systematics. John Wiley \& Sons, Chichester, United Kingdom.

López, Z., Vila, J., Ortega-Calvo, J.J., Grifoll, M., 2008. Simultaneous biodegradation of creosote-polycyclic aromatic hydrocarbons by a pyrene-degrading Mycobacterium. Applied Microbiology and Biotechnology 78, 165-172. 
Ludwig, W., Bauer, S.H., Bauer, M., Held, I., Kirchhof, G., Schulze, R., Huber, I., Spring, S., Hartmann, A., Schleifer, K.H., 1997. Detection and in situ identification of representatives of a widely distributed new bacterial phylum. Fems Microbiology Letters 153, 181-190.

Maliszewska-Kordybach, B., Smreczak, B., 2000. Ecotoxicological activity of soils polluted with polycyclic aromatic hydrocarbons (PAHS) - Effect on plants. Environmental Technology 21, 1099-1110.

Miya, R.K., Firestone, M.K., 2000. Phenanthrene-degrader community dynamics in rhizosphere soil from a common annual grass. Journal of Environmental Quality 29, 584-592.

Miya, R.K., Firestone, M.K., 2001. Enhanced phenanthrene biodegradation in soil by slender oat root exudates and root debris. Journal of Environmental Quality 30, 1911-1918.

Nayak, A.S., Sanganal, S.K., Mudde, S.K., Oblesha, A., Karegoudar, T.B., 2011. A catabolic pathway for the degradation of chrysene by Pseudoxanthomonas sp PNK-04. Fems Microbiology Letters 320, 128-134.

Newman, L.A., Reynolds, C.M., 2004. Phytodegradation of organic compounds. Current Opinion in Biotechnology 15, 225-230.

Ofosubudu, K.G., Fujita, K., Ogata, S., 1990. Excretion of ureide and other nitrogenous compounds by the root-system of soybean at different growth-stages Plant and Soil 128, 135-142.

Olson, P.E., Castro, A., Joern, M., DuTeau, N.M., Pilon-Smits, E.A.H., Reardon, K.F., 2007. Comparison of plant families in a greenhouse phytoremediation study on an aged polycyclic aromatic hydrocarbon-contaminated soil. Journal of Environmental Quality 36, 1461-1469.

Ortega-Calvo, J.J., Marchenko, A.I., Vorobyov, A.V., Borovick, R.V., 2003. Chemotaxis in polycyclic aromatic hydrocarbon-degrading bacteria isolated from coal-tar- and oil-polluted rhizospheres. Fems Microbiology Ecology 44, 373-381.

Ortega-Calvo, J.J., Saiz-Jimenez, C., 1998. Effect of humic fractions and clay on biodegradation of phenanthrene by a Pseudomonas fluorescens strain isolated from soil. Applied and Environmental Microbiology 64, 3123-3126.

Pandya, S., Iyer, P., Gaitonde, V., Parekh, T., Desai, A., 1999. Chemotaxis of Rhizobium SP.S2 towards Cajanus cajan root exudate and its major components. Current Microbiology 38, 205209.

Parrish, Z.D., Banks, M.K., Schwab, A.P., 2005. Effect of root death and decay on dissipation of polycyclic aromatic hydrocarbons in the rhizosphere of yellow sweet clover and tall fescue. Journal of Environmental Quality 34, 207-216.

Rentz, J.A., Alvarez, P.J.J., Schnoor, J.L., 2005. Benzo[a]pyrene co-metabolism in the presence of plant root extracts and exudates: Implications for phytoremediation. Environmental Pollution $136,477-484$. 
770 Smith, K.E.C., Thullner, M., Wick, L.Y., Harms, H., 2009. Sorption to Humic Acids Enhances

771 Polycyclic Aromatic Hydrocarbon Biodegradation. Environmental Science \& Technology 43,

$772 \quad 7205-7211$.

773

774

775

776

777

778

779

780

781

782

783

784

785

786

787

788

789

790

791

792

793

794

795

796

797

798

799

800

801

802

803

804

Tejeda-Agredano, M.C., Gallego, S., Niqui-Arroyo, J.L., Vila, J., Grifoll, M., Ortega-Calvo, J.J., 2011. Effect of interface fertilization on biodegradation of polycyclic aromatic hydrocarbons present in nonaqueous-phase liquids. Environmental Science \& Technology 45, 1074-1081.

Vila, J., Nieto, J.M., Mertens, J., Springael, D., Grifoll, M., 2010. Microbial community structure of a heavy fuel oil-degrading marine consortium: linking microbial dynamics with polycyclic aromatic hydrocarbon utilization. Fems Microbiology Ecology 73, 349-362.

Viñas, M., Sabate, J., Espuny, M.J., Solanas, A.M., 2005. Bacterial community dynamics and polycyclic aromatic hydrocarbon degradation during bioremediation of heavily creosotecontaminated soil. Applied and Environmental Microbiology 71, 7008-7018.

Wrenn, B.A., Venosa, A.D., 1996. Selective enumeration of aromatic and aliphatic hydrocarbon degrading bacteria by a most-probable-number procedure. Canadian Journal of Microbiology 42, 252-258.

Yi, H., Crowley, D.E., 2007. Biostimulation of PAH degradation with plants containing high concentrations of linoleic acid. Environmental Science \& Technology 41, 4382-4388.

Yrjala, K., Keskinen, A.K., Akerman, M.L., Fortelius, C., Sipila, T.P., 2010. The rhizosphere and PAH amendment mediate impacts on functional and structural bacterial diversity in sandy peat soil. Environmental Pollution 158, 1680-1688.

Zhang, H., Sekiguchi, Y., Hanada, S., Hugenholtz, P., Kim, H., Kamagata, Y., Nakamura, K., 2003. Gemmatimonas aurantiaca gen. nov., sp nov., a gram-negative, aerobic, polyphosphateaccumulating micro-organism, the first cultured representative of the new bacterial phylum Gemmatimonadetes phyl. nov. International Journal of Systematic and Evolutionary Microbiology 53, 1155-1163.

Zheng, X.Y., Sinclair, J.B., 1996. Chemotactic response of Bacillus megaterium strain B153-2-2 to soybean root and seed exudates. Physiological and Molecular Plant Pathology 48, 21-35. 


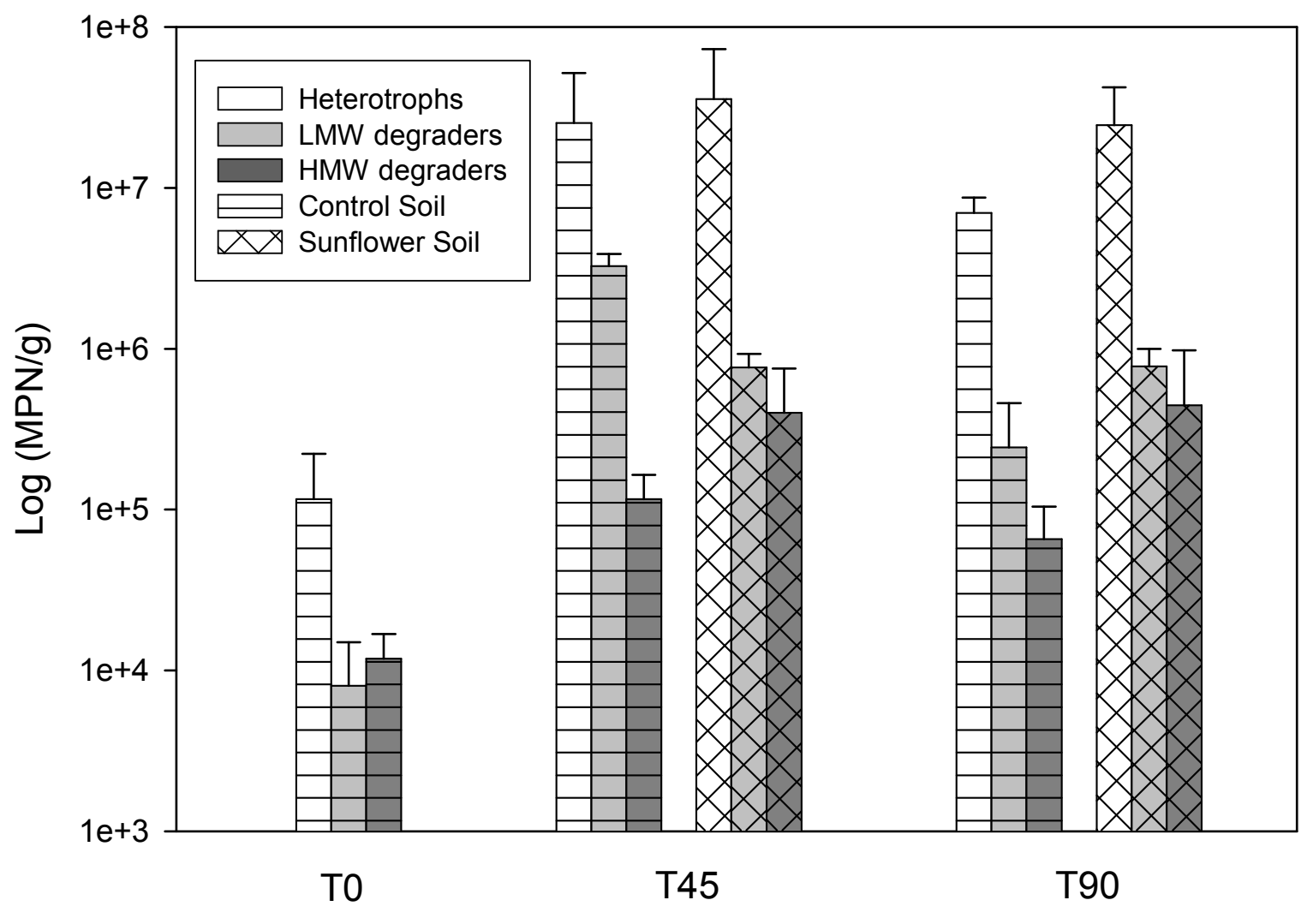

Fig. 1. Counts of heterotrophic and PAH-degrading microbial populations in the soil under the different treatments applied in the greenhouse experiment. MPN, most probable number. LMW, low-molecular-weight PAHs. HMW, high-molecularweight PAHs. T0, at the beginning of the experiment; T45, at 45 days after; T90 at 90 days after. Error bars represent the standard deviation of triplicates. 


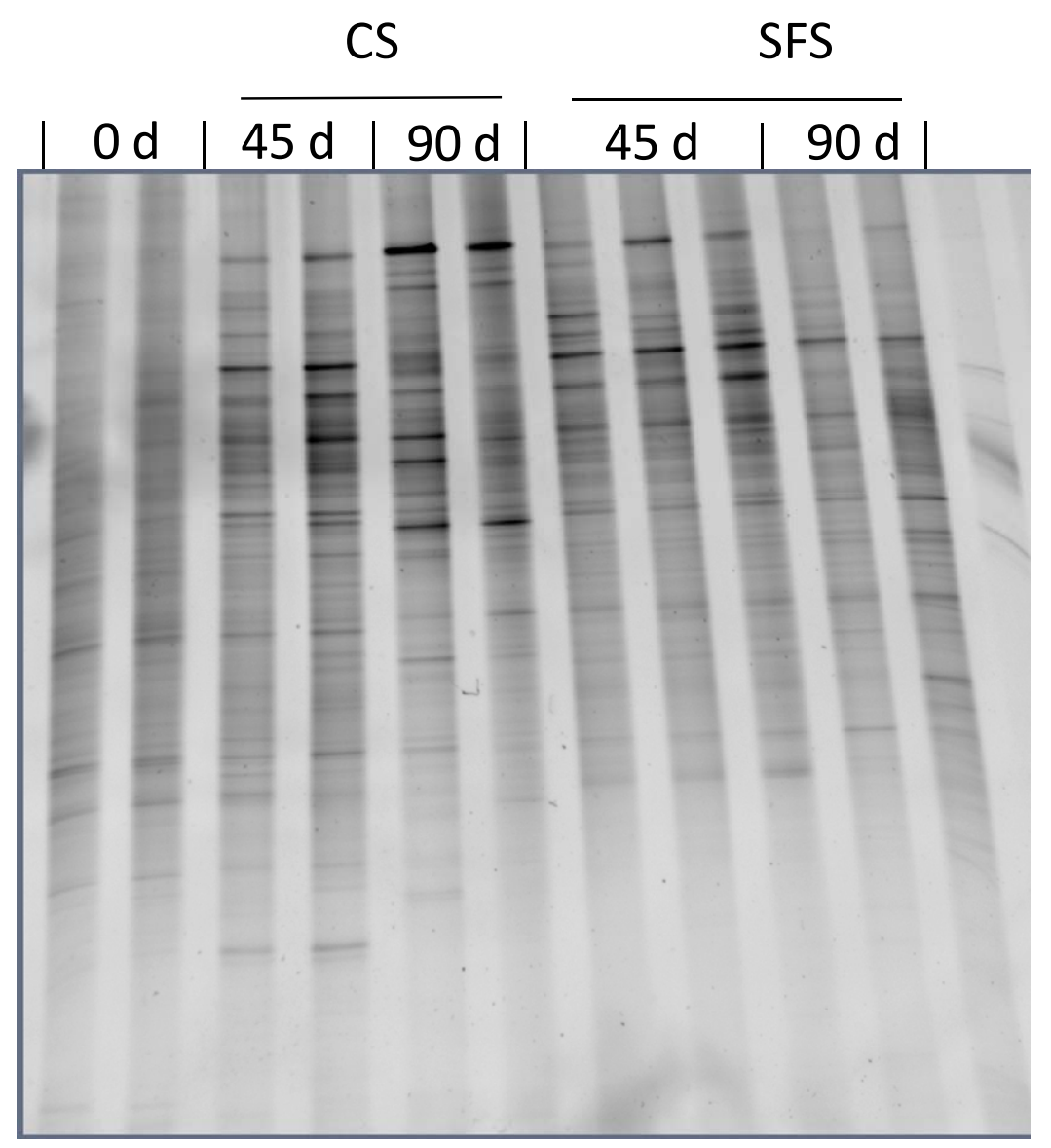
after 0, 45 and 90 days. Each lane was loaded with an identical amount of DNA. 
A

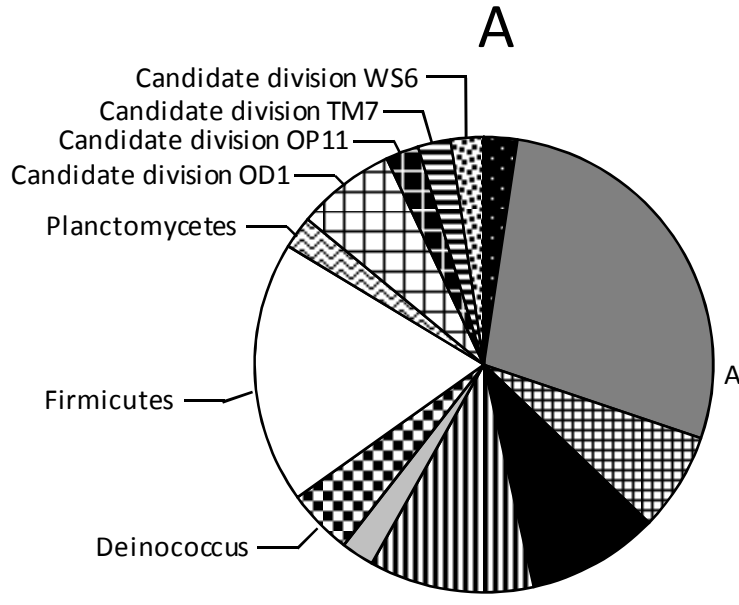

849

850

851

852
B

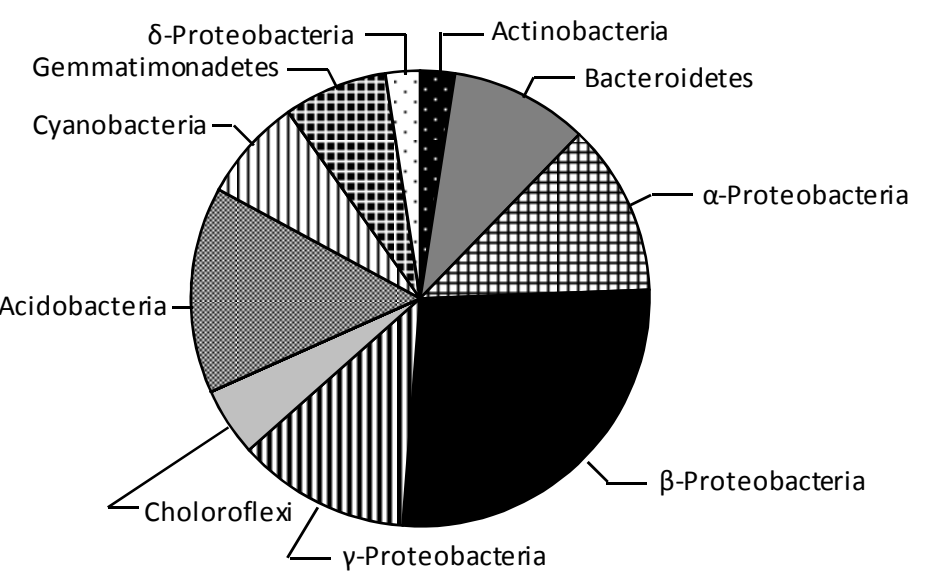

Fig. 3. Relative abundance of eubacterial phylogenetic groups identified in control soil (A) and sunflower rhizosphere soil (B) samples after 90 days of incubation in the greenhouse experiment. 
Fig. 4. Mineralization of pyrene in soil suspensions in the absence (o) and 874

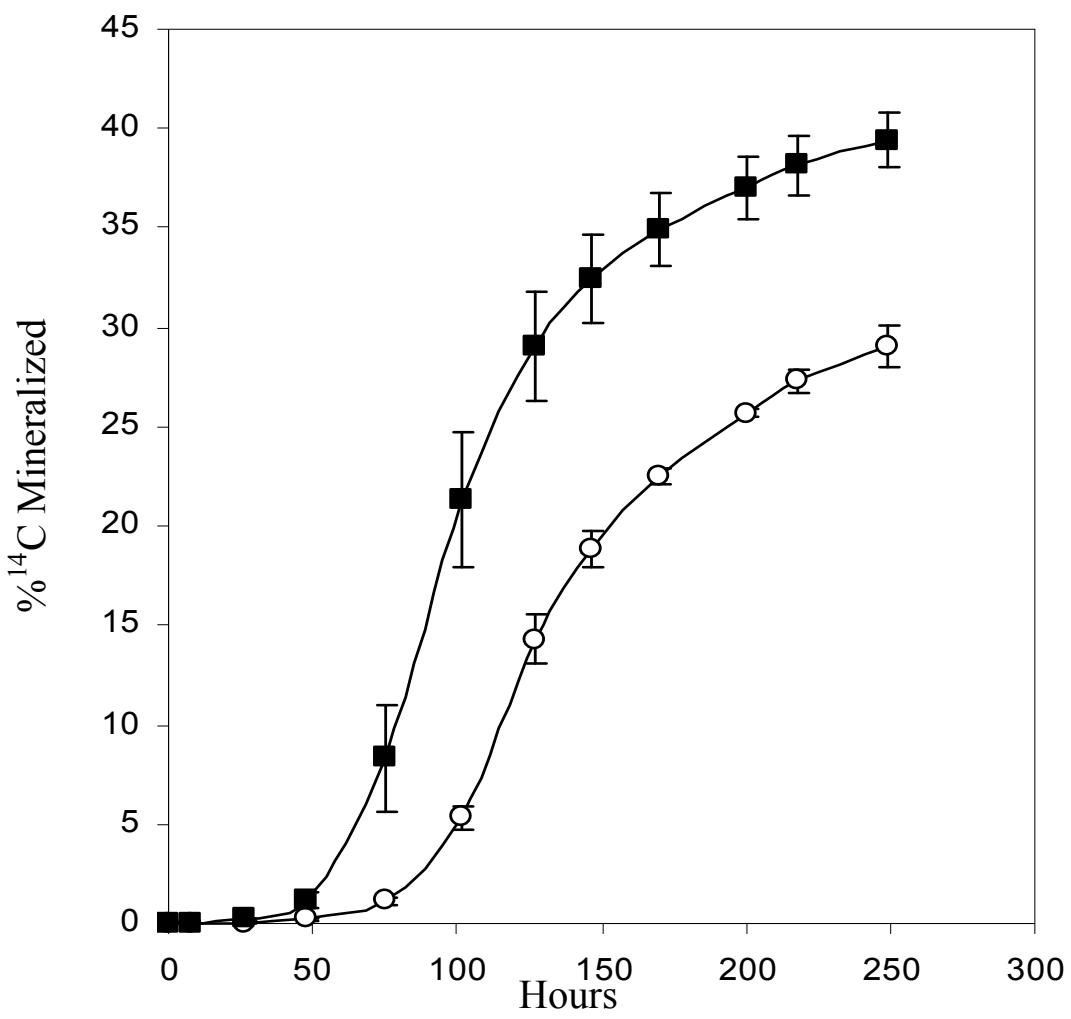

presence ( $\mathbf{a})$ of sunflower root exudates. Error bars represent the standard deviation of duplicates. 
Fig. 5. DGGE profile of PCR-amplified 16S rRNA gene fragments in samples from soil suspensions in the bioaccessibility experiment presented in Figure 4 at the beginning $(0 \mathrm{~d})$ and at the end of the experimental period $(10 \mathrm{~d})$. 
Table 1

883 Effect of planting with sunflowers on residual PAH contents $\left(\mathrm{mg} \mathrm{kg}^{-1}\right)$ in soil under greenhouse 884 conditions after 45 and 90 days.

\begin{tabular}{|c|c|c|c|c|c|}
\hline \multirow{2}{*}{ PAHs } & \multirow{2}{*}{$\mathbf{C}_{0}$} & \multicolumn{2}{|c|}{45 days } & \multicolumn{2}{|c|}{90 days } \\
\hline & & Control & Planted & Control & Planted \\
\hline Fluorene & $1.23 \pm 0.08 \mathrm{~A}$ & $0.18 \pm 0.03 \mathrm{~B}$ & $0.04 \pm 0.01 \mathrm{C}$ & $<0.00 \mathrm{C}$ & $<0.00 \mathrm{C}$ \\
\hline Phenanthrene & $3.98 \pm 0.29 \mathrm{~A}$ & $0.77 \pm 0.06 \mathrm{~B}$ & $0.39 \pm 0.03 \mathrm{~B}$ & $0.54 \pm 0.05 B$ & $0.12 \pm 0.05 \mathrm{~B}$ \\
\hline Anthracene & $8.14 \pm 0.39 \mathrm{~A}$ & $2.14 \pm 0.45 B$ & $0.67 \pm 0.14 \mathrm{C}$ & $1.63 \pm 0.37 \mathrm{~B}$ & $0.36 \pm 0.13 \mathrm{C}$ \\
\hline Fluoranthene & $5.10 \pm 0.07 \mathrm{~A}$ & $1.51 \pm 0.53 \mathrm{~B}$ & $0.46 \pm 0.01 \mathrm{C}$ & $1.47 \pm 0.14 \mathrm{~B}$ & $0.37 \pm 0.11 \mathrm{C}$ \\
\hline Pyrene & $2.04 \pm 0.05 \mathrm{~A}$ & $0.39 \pm 0.13 \mathrm{~B}$ & $0.15 \pm 0.001 \mathrm{C}$ & $0.34 \pm 0.03 B$ & $0.14 \pm 0.05 \mathrm{C}$ \\
\hline Chrysene & $1.26 \pm 0.05 \mathrm{~A}$ & $1.16 \pm 0.08 \mathrm{~A}$ & $0.68 \pm 0.12 \mathrm{~B}$ & $1.02 \pm 0.07 \mathrm{~A}$ & $0.51 \pm 0.16 \mathrm{~B}$ \\
\hline Total PAHs & $21.75 \pm 0.9 A$ & $6.15 \pm 1.26 B$ & $2.39 \pm 0.30 \mathrm{C}$ & $4.99 \pm 0.66 B$ & $1.50 \pm 0.5 C$ \\
\hline
\end{tabular}

885

$886 \mathrm{C}_{\mathrm{o}}$, initial concentration of PAHs in the soil. The values shown are the mean \pm standard deviation

887 of triplicates. Values in a row followed by the same capital letter are not significantly different $888 \quad(\mathrm{P} \leq 0.05)$. 
889 Table 2

890 Sequence analysis of the 16S rRNA gene clone libraries from the PAH-polluted control soil (without plants)

891 and sunflower rhizosphere soil at the end of the greenhouse experiment (90 days).

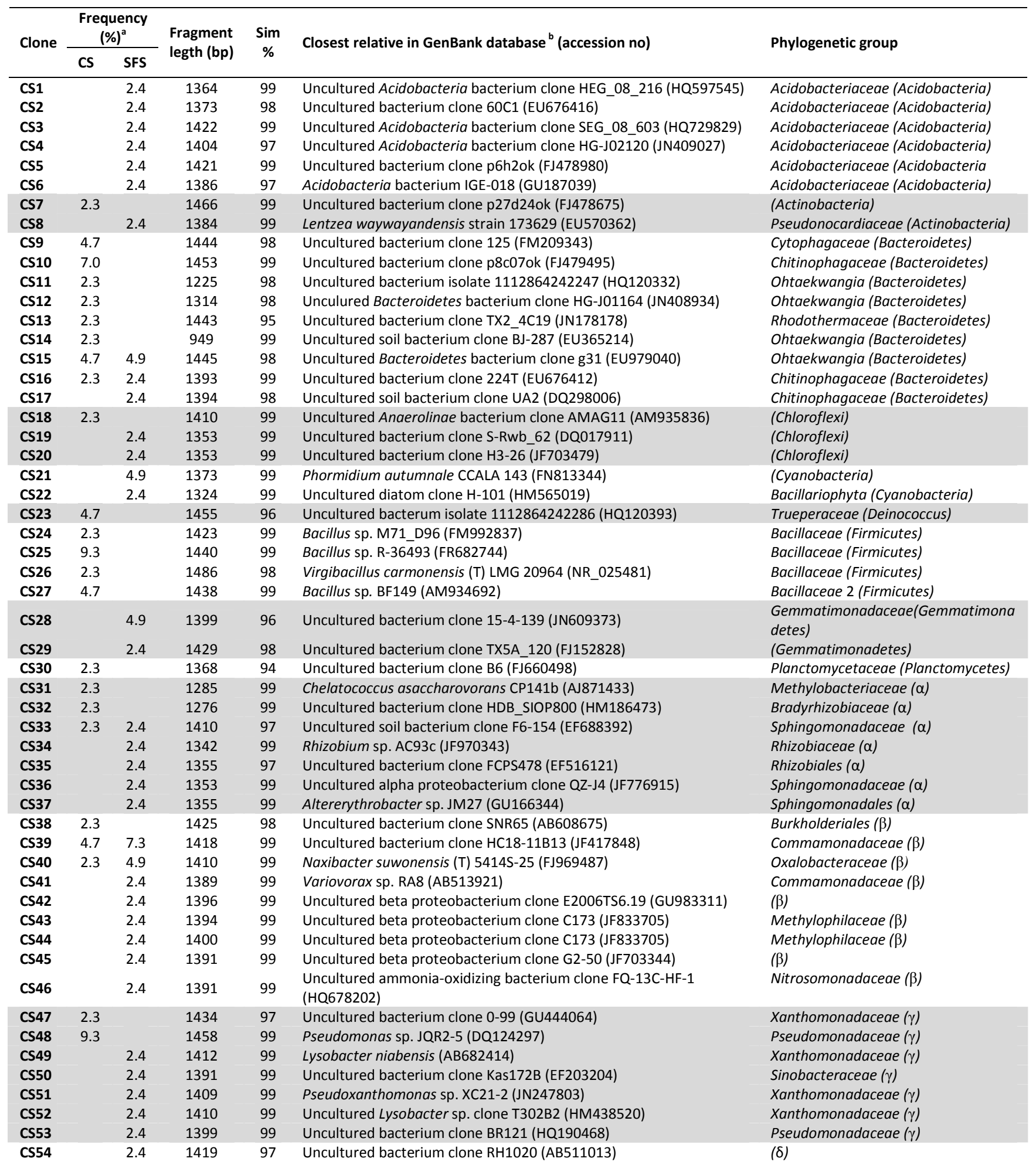




\begin{tabular}{lllllll} 
CS55 & 7.0 & 1050 & 87 & $\begin{array}{l}\text { Uncultured candidate division OD1 bacterium clone AKYH1067 } \\
\text { (AY922093) }\end{array}$ & Candidate division OD1 \\
CS56 & 2.3 & 1396 & 94 & Uncultured bacterium clone B03-05G (FJ542974) & Candidate división OP11 & Candidate división TM7 \\
CS57 & 2.3 & 1368 & 97 & Uncultured bacterium clone N1903_34 (EU104291) & Candidate division WS6 \\
\hline CS58 & 2.3 & 1250 & 93 & Uncultured bacterium clone FF_-aag84c04 (EU469637) & \\
\hline
\end{tabular}

892

893 a Frequencies in clone libraries obtained from CS (control soil) and SFS (sunflower soil). ${ }^{\mathrm{b}}$ In sequences showing an

894 identical match to uncultured and to isolated strains, only the latter are listed. Sequences with more than $94 \%$ identity

895 are grouped. $\alpha, \beta, \gamma, \delta$ correspond to alpha-, beta-, gamma- and deltaproteobacteria, respectively. Clones with

896 sequences belonging to the same phyla or subphyla (in case of Proteobacteria) are grouped and marked with

897 alternatively shade and non shaded backgrounds

898 
Table 3.

900 Organic compounds identified in the sunflower root exudates obtained in vitro after 30 days of $901 \quad$ culture.

\begin{tabular}{|c|c|c|}
\hline Class of compounds & Single compounds & $\begin{array}{c}\text { Concentration } \\
(\mathrm{ppm})\end{array}$ \\
\hline \multirow[t]{2}{*}{ Sugars $^{1}$} & Galactose & 1.16 \\
\hline & Fructose & 2.44 \\
\hline \multirow[t]{19}{*}{ Amino acids ${ }^{1}$} & Phenyl serine & 0.423 \\
\hline & Taurine & 0.083 \\
\hline & Phosphoethanolamine & 0.571 \\
\hline & Aspartic acid & 0.035 \\
\hline & Threonine & 0.034 \\
\hline & Serine & 0.069 \\
\hline & Asparagine & 0.593 \\
\hline & Glutamine & 0.301 \\
\hline & Glycine & 0.016 \\
\hline & Alanine & 0.017 \\
\hline & Cysteine & 0.003 \\
\hline & Isoleucine & 0.025 \\
\hline & Leucine & 0.026 \\
\hline & Tyrosine & 0.029 \\
\hline & Phenylalanine & 0.012 \\
\hline & Ornithine & 0.008 \\
\hline & Lysine & 0.024 \\
\hline & Histidine & 0.074 \\
\hline & Arginine & 0.078 \\
\hline \multirow[t]{5}{*}{ Fatty acids ${ }^{3}$} & Azelaic acid ${ }^{2}$ & $\mathrm{nq}$ \\
\hline & Myristic acid ${ }^{2}$ & $\mathrm{nq}$ \\
\hline & Palmitic acid ${ }^{1}$ & 0.0353 \\
\hline & ${\text { Linoleic } \text { acid }^{2}}^{2}$ & $\mathrm{nq}$ \\
\hline & Stearic acid ${ }^{1}$ & 0.0425 \\
\hline
\end{tabular}


Aromatic organic

acids $^{3}$

Terpenoids $^{3}$

902
Phtalic acid ${ }^{1}$

Paraben $^{2}$

Protochatechuic $^{1}$

Gallic acid ${ }^{2}$

5-Acetylsalicylic acid ${ }^{2}$

Abietic acid ${ }^{2}$

Hydroxydehydroabietic acid ${ }^{2}$
0.04358

$\mathrm{nq}$

0.00388

$\mathrm{nq}$

nq

nq

nq

$\mathrm{Nq}$

903 NIST library ${ }^{2}$. Identified as their methylated derivates ${ }^{3}$ (diazomethane); nq= not quantified.

904 


\begin{tabular}{cccc}
\hline $\boldsymbol{P A H s}$ & $\boldsymbol{C}_{\boldsymbol{0}}$ & $\boldsymbol{C}$ Control & Exudates \\
& & & \\
\hline Fluorene & $0.47 \pm 0.21 \mathrm{~A}$ & $0.02 \pm 0.009 \mathrm{~B}$ & $0.09 \pm 0.07 \mathrm{~B}$ \\
Phenanthrene & $4.55 \pm 0.18 \mathrm{~A}$ & $1.55 \pm 0.06 \mathrm{~B}$ & $1.02 \pm 0.16 \mathrm{C}$ \\
Anthracene & $5.83 \pm 2.43 \mathrm{~A}$ & $0.10 \pm 0.02 \mathrm{~B}$ & $0.09 \pm 0.02 \mathrm{~B}$ \\
Fluoranthene & $4.73 \pm 0.44 \mathrm{~A}$ & $1.73 \pm 0.85 \mathrm{~B}$ & $0.69 \pm 0.19 \mathrm{~B}$ \\
Pyrene & $0.98 \pm 0.12 \mathrm{~A}$ & $0.53 \pm 0.09 \mathrm{~B}$ & $0.15 \pm 0.007 \mathrm{C}$ \\
Chrysene & $1.54 \pm 0.20 \mathrm{~A}$ & $0.79 \pm 0.15 \mathrm{~B}$ & $0.47 \pm 0.02 \mathrm{C}$ \\
Total PAHs & $\mathbf{1 9 . 2 8} \pm \mathbf{1 . 4 0 A}$ & $\mathbf{4 . 7 7} \pm \mathbf{0 . 5 5 B}$ & $\mathbf{2 . 5 0} \pm \mathbf{0 . 1 6 C}$ \\
\hline
\end{tabular}

910 $(\mathrm{P} \leq 0.05)$. 